\title{
Acute pancreatitis in children: A single center experience over ten years
}

\author{
Elif Sağ${ }^{1}$, Gülay Kaya ${ }^{2}$, Elif Bahat-Özdoğan ${ }^{3}$, Süleyman Caner Karahan, \\ Mustafa İmamoğlu ${ }^{5}$, Haluk Sarıhan ${ }^{5}$, Murat Çakır ${ }^{1}$ \\ Departments of ${ }^{1}$ Pediatric Gastroenterology, Hepatology and Nutrition, ${ }^{2}$ Pediatric Intensive Care ${ }^{3}$ Pediatric Nephrology, \\ ${ }^{4}$ Medical Biochemistry, and 5Pediatric Surgery, Karadeniz Technical University, Faculty of Medicine, Trabzon, Turkey. \\ E-mail: muratcak@hotmail.com \\ Received: 16th August 2017, Revised: 26th September 2017, Accepted: 30th October 2017
}

SUMMARY: Sağ E, Kaya G, Bahat-Özdoğan E, Karahan SC, İmamoğlu M, Sarıhan $\mathrm{H}$, Çakır M. Acute pancreatitis in children: A single center experience over ten years. Turk J Pediatr 2018; 60: 153-158.

Acute pancreatitis (AP) is an inflammatory disease characterized by sudden onset abdominal pain together with elevation of pancreatic enzymes and radiographic changes. Increased incidence of AP in children have been reported in recent reports. In this study; we aimed to analyze the demographic characteristics, etiology, outcome and incidence of AP among hospitalized children in our center. Medical records of the children with AP since January 2005 were analyzed from hospital files $(\mathrm{N}=63)$. Major etiologies were systemic diseases $(14.3 \%)$, trauma $(11.1 \%)$, cholelithiasis $(9.5 \%) ; 54 \%$ $(\mathrm{N}=34)$ of the patients had mild AP, while $28.6 \%(\mathrm{~N}=18)$ had moderately severe AP and $17.4 \%(\mathrm{~N}=11)$ had severe AP. Organ dysfunction was found in 11 patients $(17.4 \%)$ at initial examination. During the follow-up period (68.1 \pm 24.3 months), 10 patients $(15.9 \%)$ experienced 24 recurring AP (RAP) attacks. Male gender, presence of local pancreatic or systemic complications at initial attack, metabolic and hereditary diseases were associated with the increased risk of RAP $(\mathrm{p}<0.05$ for all). The mortality rate associated with AP was $4.84 \%$. There was an increase in the incidence of AP since 2010 (9.57 in $2009-2010$ vs. $39.17 / 10,000$ patients in $2015-2016$ years; $p=0.0002$; OR: 4.1) among the hospitalized patients. Our results indicate that AP is a mild disease in children and the incidence is increasing among hospitalized children. Male gender, presence of local pancreatic or systemic complications at initial attack, metabolic diseases and hereditary diseases were associated with the increased risk of RAP.

Key words: acute pancreatitis, etiology, incidence, recurrence.

Acute pancreatitis (AP) is an inflammatory disease characterized by sudden onset abdominal pain together with elevation of pancreatic enzymes in the serum and/or urine and radiographic changes in the pancreas. Although it is rare in children, it is one of the main causes of morbidity/mortality in children presenting with acute abdominal pain in the emergency department ${ }^{1}$. The complications may be seen in approximately in a quarter of cases with AP, and the morbidity/mortality rate is increased in the presence of complications. ${ }^{1,2} \mathrm{It}$ must be considered in the differential diagnosis of children presenting with acute abdominal pain, and appropriate treatment must be started without any delay.
Etiology, presenting features, clinical outcome and natural history of the disease in children is different from adults. ${ }^{2-4}$ In addition; adult pancreatitis has been increasing in the 4 decades due to increased alcohol consumption and gallstone pancreatitis. ${ }^{5}$ Increased incidence of AP in children have been also reported in recent reports but most of these data are confined to specific geographic locations. It is unclear that this increment is related to local factors or real epidemiological increase of this disease. ${ }^{6-9}$

In this study, we aimed to analyze the demographic characteristics, etiologies, clinical findings and outcomes of children with AP, and 
to analyze whether the incidence of AP among the hospitalized pediatric patients is increased or not in our unit.

\section{Material and Methods}

Medical records of the children who had the final diagnosis of AP since January 2005 were analyzed from the hospital files. The diagnosis of AP was made; based on the presence of 2 of these 3 variables: (i) clinical symptoms associated with AP such as abdominal pain, nausea and vomiting, (ii) elevated serum amylase levels [ $>3 \times$ UNL (upper normal limit); normal range $<100 \mathrm{U} / \mathrm{L}]$ and/or elevated serum lipase levels ( $>3 \times \mathrm{XNL}$; normal range $<70 \mathrm{U} / \mathrm{L}$ ), and (iii) radiological changes associated with pancreatitis ${ }^{10}$. Other potential causes of amylase/lipase elevations, such as parotitis, mumps encephalitis, appendicitis, macroamylasemia and peritonitis were excluded. Recurrent AP (RAP) was defined as the recurrence of AP-related symptoms, laboratory and radiological findings at least one month later after improving the clinical and laboratory findings of initial AP attack. ${ }^{10}$

Demographic features, clinical findings and outcome including morbidity/mortality of the patients were recorded from the hospital files. The severity of AP was classified as mild, moderately severe and severe AP according to the criteria defined by NASPGHAN Pancreas Committee. ${ }^{11}$

\section{Statistical analysis}

Data were expressed as mean \pm standard deviation (SD) for continuous variables and numbers with percentages (\%) for categorical variables. At comparison of group measurement data, Student's t test was used for normally distributed data and the Mann-Whitney U test for non-normally distributed data. The chisquare test was applied in the comparison of non-measurement categorical data. The number of inpatients in all pediatric services had been determined each year since 2005 and the incidence of AP among hospitalized children was calculated in six time spans (2005-2006, 2007-2008, 2009-2010, 2011-2012, 2013-2014 and 2015-2016). p values $<0.05$ were regarded as significant.

Ethical approval was obtained for the study from the local ethical committee (2015/144).

\section{Results}

Since January $2005 ; 63$ patients $(50.8 \%$ female, mean age $9.6 \pm 4.8$ years and $23.8 \% \leq 5$ years old) were admitted with $87 \mathrm{AP}$ attacks to our pediatric gastroenterology unit. Clinical findings compatible with AP were present in 86/87 attacks (98.9\%), elevated serum amylase and/or lipase in 86/87 attacks (98.9\%) and radiological findings in 63/87 attacks $(72.4 \%)$. The main symptom at presentation was acute onset abdominal pain $(n=69,79.3 \%)$, and vomiting $(\mathrm{N}=11,12.6 \%)$ and irritability $(\mathrm{N}=5$, $5.7 \%)$. One patient $(1.1 \%)$ did not have any symptoms related with AP; and the patient was diagnosed based on elevated amylase and lipase levels accompanying with radiological findings that were consulted after intracranial tumor surgery.
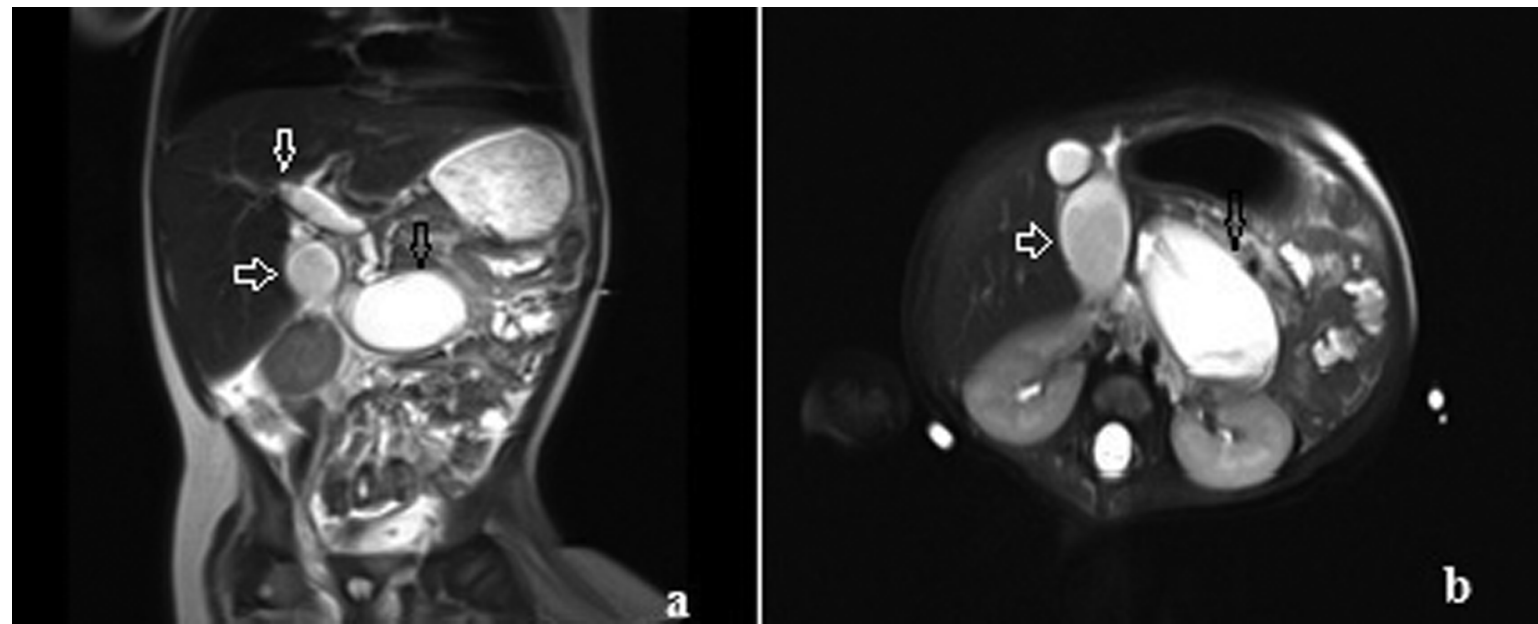

Fig. 1. Magnetic resonance cholangiopancreatography (MRCP) of the patient. Black arrows show migrated Foley that pressed ampulla of Vater and white arrows show dilated bile ducts. 
The major etiologic factors in 63 patients were; systemic diseases in nine patients $(14.3 \%)$, trauma in seven $(11.1 \%)$, cholelithiasis in six (9.5\%), drugs in four $(6.3 \%)$, metabolic diseases in four $(6.3 \%)$, and diabetic ketoacidosis in three $(4.8 \%)$. Etiological factor could not be identified in 16 patients $(\mathrm{N}=16,25.4 \%$; Table I). One patient, who was fed with percutaneous endoscopic gastrostomy in intensive care unit, had gastrointestinal bleeding, cholestasis and elevated amylase levels. Magnetic resonance cholangiopancreatography (MRCP) revealed dilatation on common bile duct and third and fourth part of duodenum. It was noticed that the urinary Foley probe was used for the gastrostomy catheter, and the balloon of Foley probe was migrated to duodenum and pressed ampulla of Vater. The patient's symptoms disappeared after extinguishing the balloon's air (Fig. 1).

The classification of severity of initial AP attack of 63 patients is shown in Figure 2; $54 \%(\mathrm{~N}=34)$ of the patients had mild AP, while $28.6 \%(\mathrm{~N}=18)$ had moderately severe AP and $17.4 \%(\mathrm{~N}=11)$ had severe AP. Organ dysfunction was found in 11 patients (17.4\%) at initial examination, and all of them persisted during the follow-up.

During the follow-up period $(68.1 \pm 24.3$ months), 10 patients (15.9\%) experienced 24 recurring AP attacks during the followup within the median 10 months (range; 1 month-2 years). Recurring AP attacks developed nine times in one patient, four in one, three in one, two in one and one in six patients. Of these, three patients had metabolic diseases, two had hereditary causes (heterozygote N29I

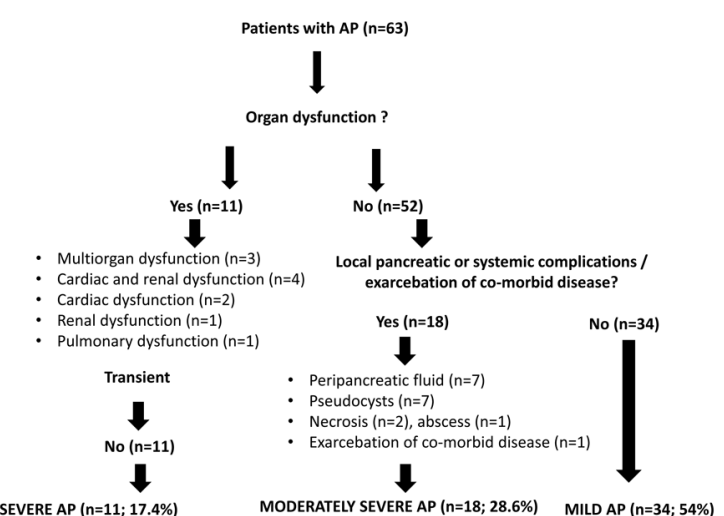

Fig. 2. Classification of severity of acute pancreatitis. Note that approximately half of the patients had mild hepatitis.. mutation in PRSS1 gene in one, heterozygote NM 002769.4 mutation in PRSS1 gene in one) and two had multiple systemic traumas. After extensive laboratory evaluations; no etiologic factor could be found in three patients for the recurrence. Patients with $(\mathrm{N}=10)$ and without RAP $(\mathrm{N}=53)$ were compared, and found that male gender $(80 \%$ vs. $43.4 \%, \mathrm{p}=0.04$, OR: 5.2 ), presence of local pancreatic or systemic complications at initial attack $(80 \%$ vs. $43.4 \%$, $\mathrm{p}=0.04$, OR: 5.2$)$, metabolic diseases $(30 \%$ vs. $1.9 \%, \mathrm{p}=0.01, \mathrm{OR}: 22.3)$ and hereditary diseases ( $20 \%$ vs. $0 \%, \mathrm{p}=0.01$, OR: 31.5$)$ were associated with the increased the risk of RAP after initial AP (Table II). On follow-up, chronic pancreatitis developed in one patient ( $10 \%$ of patients with RAP and $1.5 \%$ of all patients with AP) with cystic fibrosis.

The mortality rate associated with AP was $4.84 \%(n=4)$; two of the patients had systemic diseases (HUS), one patient had drowning and one patient had AP secondary to blind abdominal trauma.

There was an increase in the incidence of AP among hospitalized children since 2010 (Fig. $3)$. The incidence of AP among hospitalized children increased from 9.57 to 39.17 patients per 10000 patients from 2009-2010 to 20152016 years $(p=0.0002$, OR: 4.1$)$.

\section{Discussion}

In this retrospective study; we found that (i) AP may have various types of etiologies in childhood including systemic diseases (14.3\%), trauma (11.1\%) and cholelithiasis $(9.5 \%)$, but etiological factor could not be

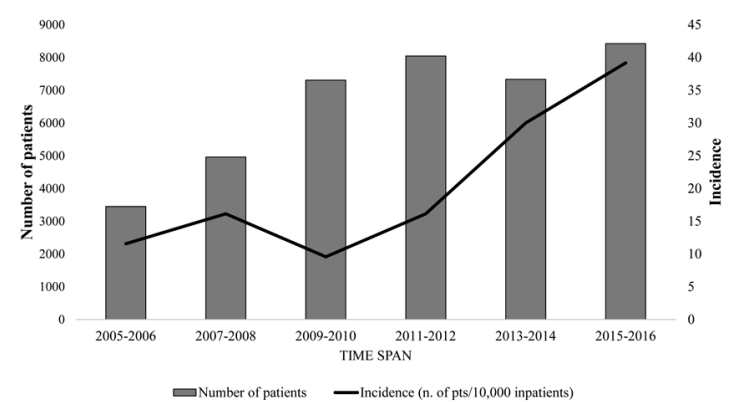

Fig. 3. Incidence of acute pancreatitis among hospitalized patients. Note the incidence is increased since 2010; and the increment is significant in 2015-2016 compared to 2009-2010 (39.17/10,000 vs. 9.57/10,000; $\mathrm{p}=0.006$; OR: 3.39 , $95 \%$ CI $1.2-9.5)$. 
Table I. Etiology of Acute Pancreatitis $(\mathrm{N}=63)$.

\begin{tabular}{ll}
\hline Etiology & $\mathrm{N}(\%)$ \\
\hline Systemic diseases & $9(14.2)$ \\
Hemolytic uremic syndrome & $6(9.5)$ \\
Henoch-Schönlein purpura & $2(3.2)$ \\
Connective tissue disease & $1(1.6)$ \\
Trauma & $7(11.1)$ \\
Cholelithiasis (gallstones) & $6(9.5)$ \\
Hereditary spherocytosis & $3(4.8)$ \\
Idiopathic cholelithiasis & $3(4.8)$ \\
Drugs & $4(6.3)$ \\
Valproic acid & $3(4.8)$ \\
Propofol & $1(1.6)$ \\
Metabolic diseases & $4(6.3)$ \\
Isovaleric acidemia & $1(1.6)$ \\
3-hydroxy-3-methylglutaryl-CoA lyase deficiency & $1(1.6)$ \\
Cystic fibrosis & $1(1.6)$ \\
Familial hypertriglyceridemia & $1(1.6)$ \\
Diabetic ketoacidosis & $3(4.8)$ \\
Hereditary pancreatitis & $2(3.2)$ \\
Acute tubular necrosis & $2(3.2)$ \\
Proven viral disease & $2(3.2)$ \\
Varicella zoster virus & $1(1.6)$ \\
Mumps & $1(1.6)$ \\
Suspected viral disease & $2(3.2)$ \\
Malignancy (acute lymphoblastic leukemia) & $1(1.6)$ \\
Drowning & $1(1.6)$ \\
Bacterial sepsis & $1(1.6)$ \\
Congenital anomaly (duplication cyst) & $1(1.6)$ \\
Post-ERCP & $1(1.6)$ \\
Iatrogenic & $1(1.6)$ \\
Idiopathic & $16(25.4)$ \\
\hline
\end{tabular}

ERCP: endoscopic retrograde cholangiopancreatography

identified in approximately $25 \%$ of the patients (ii) approximately half of the patients had mild pancreatitis, (iii) approximately $15 \%$ of the patients experienced RAP attacks during follow-up, and it was more common in males, patients who developed local pancreatic or systemic complications at initial attack and patients with underlying etiology of metabolic and hereditary diseases, (iv) the incidence of the AP has increased in the last 2 years compared to 2005-2006.

In previous studies, Poddar et al. ${ }^{7}$ reported 320 children with AP, RAP and CP from Austria, and they found that trauma $(21 \%)$ and biliary diseases $(10 \%)$ were the most common causes of AP in children. Park et al. ${ }^{6}$ reported 215 children with AP from USA, and they found that biliary causes $(36.2 \%)$ and medications
(25.6\%) were the most common cause of AP. Pezzilli et al. ${ }^{12}$ reported 50 children with AP from Italy, and the most common etiological factors were biliary diseases $(20 \%)$ and viral infections $(12 \%)$. Majbar et al. ${ }^{13}$ reported 94 children from UK, and drugs (19\%) and gallstones $(13 \%)$ are the major identifiable causes of AP. Fayyaz et al. ${ }^{14}$ reported 72 children with AP from Pakistan and choledochal cyst and hyperlipidemia were the most common causes of AP. Kandula et al. ${ }^{15}$ studied 87 infants and toddlers ( $\leq 3$ years old age) with AP, and the most common etiological factors were multisystem diseases $(33.3 \%)$ and systemic infections (18.4\%). In our study, the etiology of AP was pancreatic involvement secondary to systemic diseases ( $14.3 \%$, especially HUS) and trauma $(11.1 \%)$. The difference in the 
Table II. Features of Patients with (Group 1) and without (Group 2) Recurrent Acute Pancreatitis.

\begin{tabular}{llll}
\hline Features & $\begin{array}{l}\text { Group 1 } \\
\text { (with RAP; N=10) }\end{array}$ & $\begin{array}{l}\text { Group 2 } \\
\text { (without RAP; N=53) }\end{array}$ & p value \\
\hline Age (year) & $9.5 \pm 4.9$ & $10.1 \pm 3.9$ & 0.69 \\
Duration of follow up (year) & $2.6 \pm 2.8$ & $2.1 \pm 2.3$ & 0.90 \\
Male, N (\%) & $8(80.0)$ & $23(43.4)$ & 0.04 \\
Amylase (U/L) & $842.4 \pm 917.2$ & $1,124.6 \pm 641.2$ & 0.08 \\
Maximum amylase (U/L) & $1,005.8 \pm 942.5$ & $1,220.6 \pm 627.4$ & 0.49 \\
Time to normalization (months) & $6.9 \pm 6.5$ & $7.5 \pm 9.1$ & 0.91 \\
Lipase (U/L) & $730.6 \pm 1,044.8$ & $639.3 \pm 554.4$ & 0.64 \\
White blood count (/mm $\left.{ }^{3}\right)$ & $12,887 \pm 6,869$ & $1,3631 \pm 3,522$ & 0.71 \\
Albumin (g/dl) & $4.0 \pm 0.7$ & $3.9 \pm 0.5$ & 0.81 \\
CRP (mg/dl) & $2.8 \pm 4$ & $4.9 \pm 6.8$ & 0.50 \\
Presence of complication, N (\%) & $8(80.0)$ & $23(43.4)$ & 0.04 \\
Metabolic disease, N (\%) & $3(30.0)$ & $1(1.9)$ & 0.01 \\
Hereditary disease, N (\%) & $2(20.0)$ & $0(0)$ & 0.01 \\
\hline
\end{tabular}

${ }^{*}$ CRP: C-reactive protein; RAP: recurrent acute pancreatitis

etiological factors in these studies may be related with ethnic and geographic variations. The association of AP with the systemic diseases was reported between $10-50 \%$ in previous studies, and pulmonary diseases, HUS and organ transplantations are the major causes of systemic diseases associated with AP. $1,4,6,16,17$ The association of AP with HUS has been reported in previous studies. It was reported $6.6 \%$ in infants, and up to $10 \%$ in adolescents with AP. ${ }^{15,18}$ Grodinsky et al. ${ }^{18}$ reported that $21 \%$ of the children with HUS had AP attacks during the clinical follow-up. It is well-known that the incidence of HUS is increasing in our country, and thus we will encounter this association more commonly in the near future.

In this study, we found that $15.9 \%$ of the patients had RAP. RAP was more common in males, patients with experienced local pancreatic or systemic complications at initial attack and associated with metabolic or hereditary diseases. The prevalence of RAP was reported 15 to $42 \%$ in previous studies.6,7,12,19,20 In addition to our findings, other risk factors for RAP was defined such as: young age and severe AP in initial attack, presence of pancreatic necrosis, higher procalcitonin levels and idiopathic etiology. 7,19,20 The largest study about the etiologies of children with RAP was reported by Lucidi et al. ${ }^{21}$ from Italy.
They reported 78 children with RAP and genetic predisposition was found in $42.3 \%$ of the patients, whereas etiological factor could not found in approximately $26 \%$ of the children. In contrast, $\mathrm{Su}$ et al. ${ }^{22}$ found that pancreaticobiliary anomalies $(28 \%)$ was the leading cause of RAP in children. RAP especially associated with genetic predisposition is a risk factor for the development of chronic pancreatitis in long-term.

In previous studies, mortality associated with AP were reported between $0.4-6 \%$ in children, and mainly associated with underlying etiology or comorbid conditions. ${ }^{19,23,24}$ Mortality rate was found $5.7 \%$ in a group of children with AP that were hospitalized in pediatric intensive care unit. ${ }^{25}$ Guo et al. ${ }^{26}$ found the mortality rate of $5 \%$ in children with AP, and patients with systemic inflammatory response syndrome in the first week of onset, early organ failure, and multiorgan failure in the first week of onset, infected necrosis, and idiopathic cause have higher risk of death.

In this study, we found that incidence of AP is increasing among hospitalized children in recent years. Similar findings were reported in various countries such as India, United States and Australia in population based studies. $6,7,17$ It may be related with the awareness of AP in children with mild symptoms, availability of testing amylase and lipase in the emergency 
department, and increased referral of abdominal pain to the emergency department. Our results indicate that the incidence of AP is rising among hospitalized children as in adults. Contrary to adults, AP is a mild disease in children. Male gender, presence of local pancreatic or systemic complications at initial attack, metabolic diseases and hereditary diseases were associated with the increased the risk of RAP. Mortality is generally related with underlying condition.

\section{REFERENCES}

1. Suzuki M, Sai JK, Shimizu T. Acute pancreatitis in children and adolescents. World J Gastrointest Pathophysiol 2014; 5: 416-426.

2. Forsmark CE, Vege SS, Wilcox CM. Acute pancreatitis. N Engl J Med 2016; 375: 1972-1981.

3. Husain SZ, Srinath AI. What's unique about acute pancreatitis in children: Risk factors, diagnosis and management? Nat Rev Gastroenterol Hepatol 2017; 14: 366-372.

4. Weizman Z, Durie PR. Acute pancreatitis in childhood. J Pediatr 1988; 113: 24-29.

5. Yadav D, Lowenfels AB. Trends in the epidemiology of the first attack of acute pancreatitis: A systematic review. Pancreas 2006; 33: 323-330.

6. Park A, Latif SU, Shah AU, et al. Changing referral trends of acute pancreatitis in children: A 12-year single-center analysis. J Pediatr Gastroenterol Nutr 2009; 49: 316-322.

7. Poddar U, Yachha SK, Borkar V, Srivastava A, Kumar S. A report of 320 cases of childhood pancreatitis: Increasing incidence, etiologic categorization, dynamics, severity assessment, and outcome. Pancreas 2017; 46: 110-115.

8. Pant C, Deshpande A, Olyaee M, et al. Epidemiology of acute pancreatitis in hospitalized children in the United States from 2000-2009. PLoS One 2014; 9: e95552.

9. Lopez MJ. The changing incidence of acute pancreatitis in children: a single-institution perspective. J Pediatr 2002; 140: 622-624.

10. Morinville VD, Husain SZ, Bai $\mathrm{H}$, et al.; INSPPIRE Group. Definitions of pediatric pancreatitis and survey of present clinical practices. J Pediatr Gastroenterol Nutr 2012; 55: 261-265.

11. Abu-El-Haija M, Kumar S, Szabo F, et al.; NASPGHAN Pancreas Committee. Classification of acute pancreatitis in the pediatric population: Clinical report from the NASPGHAN Pancreas Committee. J Pediatr Gastroenterol Nutr 2017; 64: 984-990.
12. Pezzilli R, Morselli-Labate AM, Castellano E, et al. Acute pancreatitis in children. An Italian multicentre study. Dig Liver Dis 2002; 34: 343-348.

13. Majbar AA, Cusick E, Johnson P, Lynn RM, Hunt LP, Shield JP. Incidence and clinical associations of childhood acute pancreatitis. Pediatrics 2016; 138: e20161198.

14. Fayyaz Z, Cheema HA, Suleman H, Hashmi MA, Parkash A, Waheed N. Clinical presentation, aetiology and complications of pancreatitis in children. J Ayub Med Coll Abbottabad 2015; 27: 628-632.

15. Kandula L, Lowe ME. Etiology and outcome of acute pancreatitis in infants and toddlers. J Pediatr 2008; 152: 106-110.

16. Mekitarian Filho E, Carvalho WB, Silva FD. Acute pancreatitis in pediatrics: A systematic review of the literature. J Pediatr (Rio J) 2012; 88: 101-114.

17. Nydegger A, Heine RG, Ranuh R, Gegati-Levy R, Crameri J, Oliver MR. Changing incidence of acute pancreatitis: 10-year experience at the Royal Children's Hospital, Melbourne. J Gastroenterol Hepatol 2007; 22: $1313-1316$.

18. Grodinsky S, Telmesani A, Robson WL, Fick G, Scott RB. Gastrointestinal manifestations of hemolytic uremic syndrome: Recognition of pancreatitis. J Pediatr Gastroenterol Nutr 1990; 11: 518-524.

19. Pant C, Sferra TJ, Lee BR, Cocjin JT, Olyaee M. Acute recurrent pancreatitis in children: A study from the pediatric health information system. J Pediatr Gastroenterol Nutr 2016; 62: 450-452.

20. Hao F, Guo H, Luo Q, Guo C. Disease progression of acute pancreatitis in pediatric patients. J Surg Res 2016; 202: 422-427.

21. Lucidi V, Alghisi F, Dall'Oglio L, et al. The etiology of acute recurrent pancreatitis in children: A challenge for pediatricians. Pancreas 2011; 40: 517-521.

22. Su WJ, Chen HL, Lai HS, Ni YH, Chang MH Pancreaticobiliary anomalies is the leading cause of childhood recurrent pancreatitis. J Formos Med Assoc 2007; 106: 119-125.

23. Lautz TB, Chin AC, Radhakrishnan J. Acute pancreatitis in children: Spectrum of disease and predictors of severity. J Pediatr Surg 2011; 46: 1144-1149.

24. Werlin SL, Kugathasan S, Frautschy BC. Pancreatitis in children. J Pediatr Gastroenterol Nutr 2003; 37: 591-595.

25. Goday PS, Wakeham M, Kuhn EM, Collins MM, Werlin SL. Acute pancreatitis in the pediatric intensive care unit. J Pediatr Gastroenterol Nutr 2015; 61: 108-112.

26. Guo Q, Li M, Chen $\mathrm{Y}, \mathrm{Hu} \mathrm{H}, \mathrm{Hu}$ W. Predictors for mortality following acute pancreatitis in children. Pediatr Surg Int 2014; 30: 1111-1115. 